\title{
Suggested Improvements on Water Treatment Plants for Sustainable Development
}

\author{
G.P.R.Abhayawardana
}

\begin{abstract}
Water is a basic human need and acquisition of safe drinking water is a major problem faced by present world. Water treatment plants are used to purify the water in to a quality suitable to be consumed by humans. Thoough there are a large number of Water Treatment Plants operating in Sabaragamuwa Province of Sri Lanka most of them are facing common problems which reduce their capacity and decrease their efficiency. In an average plant of capacity between 1000$10,000 \mathrm{~m}^{3} /$ day, the capacity should be improved by $21 \%$ to provide the existing demand. Sand/gem mining, problems due to floating debris, difficulties in maintenance, insufficient storage facilities, the implemented mechanisms not being suitable for the process, difficulties in maintenance and environmental degradation in the catchment areas are common problems faced by these plants. Key suggestions to improve Water Treatment Plants in Sabaragamuwa Province are to form plants with larger capacities to an area, to leave space for necessary augmentations when building plants, implementing strict actions on sand/gem mining within 2 kilometers from an intake, prevent floating debris to the plant, provide sufficient storage and to conserve catchment areas.
\end{abstract}

Keywords: Water, Water Treatment Plant

\section{Introduction}

Water is a vital resource for human beings. But with the increase of population and rapid development, acquiring safe, portable water is becoming a major issue. Currently, over one billion in the world are lacking safe water. [Jayawardana, A.W]

Water to be supplied for public use must be potable i.e., satisfactory for drinking purposes from the standpoint of its chemical, physical and biological characteristics. Drinking water should, preferably, be obtained from a source free from pollution. The raw water normally available from surface water sources is, however, not directly suitable for drinking purposes.

Thus, the objective of water treatment is to produce safe and potable drinking water. Though Sri Lanka has many surface and ground water bodies, with the population growth and environmental pollution, it is not feasible to utilize it as drinking water without some amount of purification.

According to the parameters of the water, the amount of treatment required is determined and most common treatment methods used for surface water are screening, aeration, pre and post chlorination, sedimentation, flocculation and filtration.
However, due to various environmental, social, technical reasons, it is evident that many problems occur related to water treatment. This study was done on 8 selected water treatment plants in Sabaragamuwa Province, to determine the common problems associated with water treatment, causes of the problems and suggestions to overcome the shortcomings in order to improve the performance of plants. All the plants under the research get water from surface water bodies.

\section{Methodology}

- The selected plants were labelled A-H according to their design capacities.

- Thus, plant A (design capacity 1150 $\mathrm{m}^{3}$ /day), B (design capacity $2100 \mathrm{~m}^{3}$ /day), $\mathrm{C}$ (design capacity $4500 \mathrm{~m}^{3} /$ day), D (design capacity $4500 \mathrm{~m}^{3} /$ day), Plant E (design capacity $6000 \mathrm{~m}^{3} /$ day), F (design capacity $6000 \mathrm{~m}^{3} /$ day), $\mathrm{G}$ (design capacity 8500 $\mathrm{m}^{3} /$ day) and $\mathrm{H}$ (design capacity 9000 $\mathrm{m}^{3} /$ day) are labelled as such for easy reference.

Eng. (Ms) G.P.R.Abhayawardana, B.Sc. Eng. (Ruhuna), Planning and Design Engineer, National Water Supply and Drainage Board, Sri Lanka 
Table 1 - Design Capacities of the Water Treatment Plants

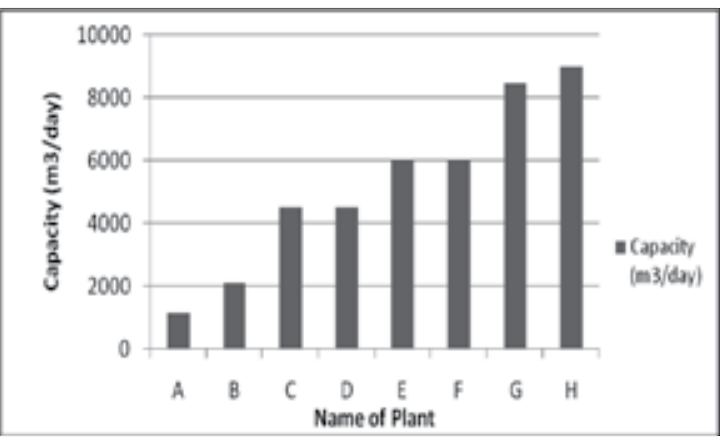

- The demands for the plants and the technical, social and environmental issues affecting the treatment plants were determined by studying the available technical data and by acquring information from treatment plant operators/workers and the general public.

\section{Issues Related to Water Treatment Plants}

In the study several problems were identified, which were affecting most of the selected treatment plants up to some extent.

The followings were among the major issues faced by the plants in Sabaragamuwa Province.

1. Capacity not being sufficient to cater the existing demand.

2. Problems occurring by gem and sand mining

3. Blocking of plant intake with floating debris.

4. Maintenance difficulties

5. Insufficient storage facilities

6. Adaptation of unsuitable mechanisms

7. Problems in the catchment areas of the water bodies.

\subsection{Difference between Demand and the Design Capacity}

The most pressing problem related to the water treatment is the difference between the design capacity and the actual demand of the plants.

Considering Table 2, it is evident that the capacities of A, B and C Plants are less than the actual demand while the design capacity is equal to the demand in Plant D.
Table 2 - Difference between Design Capacity and the Actual Demand Water Treatment Plants

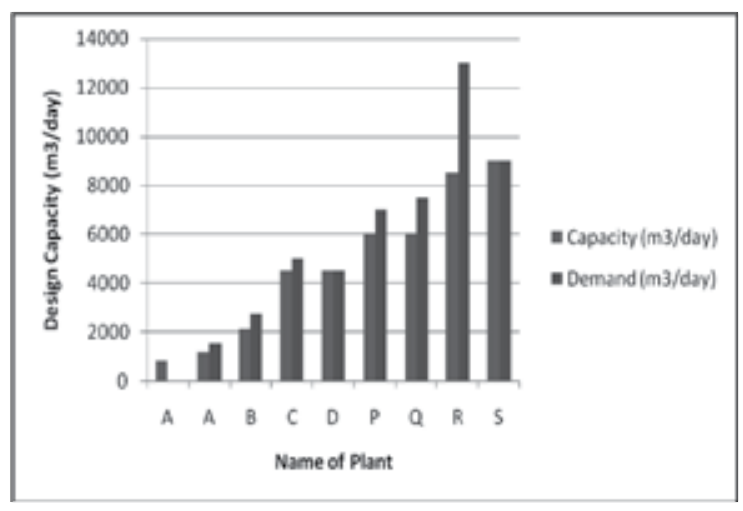

Considering the above, the capacity of an average Water Treatment Plant should be improved by $21 \%$ to cater for the existing demand of the water consumers in the area.

The plants put their maximum efforts to provide water to their consumers. However, they are not in a position to cater to the current demand.

A treatment plant is designed considering a design period of approximately 20 years. With the rapid growth of population, the number of consumers increase dramatically, thus the forecasted demand in 20 years is achieved well beforehand. The result is the insufficiency of the capacity of the plant before the design period and it causes the plant to work without stopping to provide a higher volume of treated water than the possible, designed volume. This eventually causes overloading of the plant facilities.

\subsection{Problems regarding Gem and Sand Mining.}

Sabaragamuwa Province consists of Ratnapura and Kegalle Districts where gem and sand mining are among major occupations of the residents. The uncontrolled mining in surface water bodies cause many problems including increasing of water turbidity, dropping of the water table and reduction of the stability of river banks.

\subsubsection{Increase of Water Turbidity}

When a treatment plant is designed, the existing turbidity in the relevant water source is used to design flocculator, sedimentation tank and the filters. 
However, if sand or gem mining starts on the upstream of the intake is done after the operation the plant takes place, the turbidity level will show a huge increase than the anticipated value. Thus, the capacity of the existing treatment methods is not sufficient to purify that highly turbid water.

\subsubsection{Dropping of Water Table}

The intake structure of a water treatment plant is designed according to the existing condition of the surface water body. However, sand or gem mining near the intakes causes the water level to drop dramatically in accordance with the removed sand, causing the water level to drop by meters in a considerably small period of time.

In two of the considered plants, the water level has dropped alarmingly due to excessive sand mining in one case and due to gem mining in the other. Thus it was not possible to obtain water through the former intake and the water has to be pumped from a different location.

\subsubsection{Reduction of bank stability}

In excessive mining of gem and sand, people tend to disturb the banks of the river. They dig out the bank eventually leading to reduction of the bank stabilization and occurring of erosion and landslides. If that occurs near an intake structure it can be damaged.

\subsection{Blockage of Plant Intakes}

Current operation range of water treatment system, firstly, depends of water quality and quantity in the water intake.[Zimoch., I] The surface water bodies used to get water are carrying a considerable amount of floating debris in the flow. Though screens are provided at the intakes, the debris collect at the screens and cause them to block.

It leads to reduction of plant capacity. In some cases, where the water is pumped to the plant, the lack of water entering the plant due to intake blocking with debris has caused pumps to burn out.

\subsection{Difficulties in Maintenance}

\subsubsection{Usage of plate/tube settlers}

Though the water treatment plants are designed according to the manuals, some unexpected problems can occur when they are being operated.

In many plants, plate and tube settlers are used in the sedimentation tank/clarifiers to increase its efficiency. The method to clean the tubes or plated is using a pressured water jet and then collect the sludge accumilated at the bottom of the tank with a sludge scraper. However, the operators complain that cleaning the tubes/plates using that method is not satisfactory and that a considerable amount of sludge tends to stick on the surface of the tubes/paltes and in the bottom of the tank.

As the surface of the plates/tubes should be very smooth to allow the particles to slide to the bottom, this causes problems in the settling process.

In most of the plants, the tubes/plates are permanently fixed to the tank, thus it is not even possible to get them out and clean thoroughly.

\subsubsection{Backwashing of filters}

In the design manuals, it is insisted that the sand filters need to be back washed frequently to clean them of the mud particles collected in the filter media. However, if the water demand is high, alternated filter usage has to be ruled out. The operators tend to utilize the maximum available capacity of the plant by using all the filters. If the demand is high, backwashing of the filters cause sudden termination of the water distribution in the plants where no water storage facilities are provided. Thus it causes the efficiency of the filter to reduce by a considerable amount and in the long term it can cause the mud cakes to form in the sand bed and will lead to refilling of the filter media.

However, for Rapid sand filters, sand should be replaced every year.[Mankar, S.M., et al]

\subsection{Problems related to the catchment areas}

For the water bodies to have a sufficient water flow the catchment providing water to it should be in pristine conditions. However, with the increase of population, deforestation, climatic change the conditions of the catchment areas are deteriorating and it is affecting the water supply very much. If the dry season prevails for a month or two, it causes the river flow to drop 
dramatically in a short period. Thus, the water inflow to the plants becomes less.

\subsection{Adaptation of unsuitable mechanisms}

In some of the treatment plants, chemical dosage pumps are used to add chemicals like chlorine, alum to the water. However, with the sudden rains and frequent change of the river flows the parameters of the water change rapidly and the addition of a certain amount of chemicals to every batch of water is not acceptable. Thus, inclusion of those mechanisms is unsuitable to water with varying parameters.

\section{Suggestions to improve the condition of Water Treatment Plants}

The key suggestions to improve the existing water treatment plants in Sabaragamuwa province are based on provision of solutions to the main problems that occur in the plants, making the treatment capacity or the efficiency to reduce.

When designing of a plant, the capacity is decided by analysing the expected population growth and the number of water consumers. However, it has to be noticed that building of a large scale plant is more economical, easy and feasible than building two plants with smaller capacities. If implementation of a larger plant is not possible with the available funds and affordability of the population, land area should be allocated in case augmentation of the plant is to be done in future.

Even when several smaller plants are to be implemented nearby, it is suggested to go for one larger plant.

Sand and gem mining cause severe problems to the river environment, however it is not possible to put an end to it. However, there is an act prohibiting the mining of sand/gem within two kilometres upstream and downstream of an intake structure. This should be acknowledged to the miners and if the mining prevails legal actions should be taken to put an end to it.

In the rivers and other surface water bodies in Sri Lanka, a large amount of floating debris is evident which come with the water in to the plant. However, it is not possible to provide fine screens at the intake due to blockage occurring. Thus, a suitable preventive structure or a mechanism like a floating boom should be implemented.

When implementing processes or mechanisms, practicability should be given a high priority according to conditions and the details of the each individual plant.

When using tube or plate settlers in sedimentation tanks, it is best if it can be installed as individaul units which can be taken out easily. That will make the cleaning and replacing of any damaged plates/tubes easier.

Conservation of the catchment areas should be considered very important and reforestation should be done in the crucial areas.

\section{Conclusion}

Due to the pollution of water bodies with the increase of environmental deterioration, it is necessary to treat water before usage. Thus treatment plants with different amounts of treatment are used to purify water before distributing it to the consumers. However, the efficiency and the performance of most of the treatment plants in Sabaragamuwa Province are less than satisfactory.

The common problems related to plants are having a lesser capacity than the current demand, sand/gem mining, problems due to floating debris, difficulties in maintenance, insufficient storage facilities, the implemented mechanisms not being suitable for the process and being hard to maintain and environmental degradation in the catchment areas.

It is suggested to design for larger capacity plants for an area without constructing several smaller ones and to leave space for necessary augmentations when building plants.

Strict actions should be taken about sand/gem mining within 2 kilometres from a water intake. A proper structure like a floating boom should be provided at the intake to prevent the floating debirs from entering the plant.

Whenever a plant is designed, sufficient storage facilities should be provided and conservation of the catchment areas should be given priority. 


\section{Acknowledgement}

The author wishes to express sincere gratitude to the IWMI for organizing this competition and to thank the plant operators and workers who provided the necessary information.

\section{References}

1. Jayawardana, A.W., Challenges for Sustainable Water Management, ACESP 2012, Faculty of Engineering, University of Ruhuna, Sri Lanka

2. Zimoch, I., "Water Safety Plans a method of the Management of Water Treatment Plant Operation", Silesian University of Technology, Institute of Water and Sewage Engineering, Gliwice, Poland, 2012

3. Mankar, S.M., Nagarnaik, P.B., Tech, M., "Performence Evaluation of a Water Treatment Plant", G.H.Raisoni College of Engineering, Nagpur, India, 2011 